\title{
Konversi minyak biji alpukat menjadi fraksi bahan bakar cair melalui proses catalytic cracking menggunakan katalis CuO/ZAA
}

\section{Conversion of avocado seed oil into liquid fuel fraction through catalytic cracking process using CuO/ZAA catalyst}

\author{
Junifa Layla Sihombing *; Ahmad Nasir Pulungan ${ }^{1}$; Dewi Purnama Sari ${ }^{1}$; Moondra Zubir ${ }^{1}$; Rini Selly ${ }^{1}$ \\ ${ }^{1}$ Jurusan Kimia, Fakultas Matematika dan Ilmu Pengetahuan Alam, Universitas Negeri Medan, Medan-Indonesia \\ *Korespondensi: junifalaylasihombing@gmail.com
}

\begin{abstract}
Penelitian Konversi minyak biji alpukat menjadi fraksi bahan bakar cair melalui proses catalytic cracking menggunakan katalis zeolit alam aktif terimpregnasi oksida logam $\mathrm{Cu}$ (CuO/ZAA) bertujuan untuk menghasilkan produk bahan bakar cair setaraf fraksi biogasoline dan biodiesel. Penelitian ini telah dilakukan dengan 3 tahapan utama yaitu 1) Ekstraksi Minyak Biji Alpukat, 2) Preparasi dan Karakterisasi Katalis CuO/ZAA, 3) Catalytic Cracking Minyak Biii Alpukat dengan Katalis ZAA dan $\mathrm{CuO} /$ ZAA pada temperatur proses $450^{\circ} \mathrm{C}$. Hasil konversi pada katalis ZAA dan katalis CuO/ZAA berturut-turut sebesar $8,39 \%$ dan $10,32 \%$ untuk produk cair, 0,83\% dan 0,99\% untuk kokas dan $56,89 \%$ dan $88,69 \%$ untuk residu. Dari analisis GC diperoleh selektivitas katalis ZAA dan CuO/ZAA berturut-turut adalah $61,70 \%$ dan $56,34 \%$ untuk fraksi bensin, 4,82\% dan 10,88\% untuk fraksi diesel dan $33,48 \%$ dan $32,78 \%$ untuk fraksi minyak berat. Dengan demikin disimpulkan bahwa impregnasi oksida logam $\mathrm{CuO}$ pada bahan pengemban zeolit sebagai katalis (CuO/ZAA) meningkatkan aktivitas katalitik katalis, namun selektivitas katalis CuO/ZAA terhadap fraksi bensin lebih rendah dibandingkan dengan katalis ZAA.
\end{abstract}

Kata kunci: katalis, catalytic cracking, minyak biji alpukat, CuO/ZAA, fraksi bahan bakar

Research on the conversion of avocado seed oil to liquid fuel fraction through catalytic cracking process using activated natural zeolite catalysts of $\mathrm{Cu}(\mathrm{CuO} / \mathrm{ZAA}$ ) metal oxide, aims to produce liquid fuel products equivalent to biogasoline and biodiesel fractions. This research has been done with 3 main stages namely 1) Extraction of Avocado Oil, 2) Preparation and Characterization of CuO / ZAA Catalyst, 3) Catalytic Cracking of Avocado Seed Oil with ZAA and CuO/ZAA Catalyst at 450oC process temperature. The conversion results on ZAA catalyst and CuO/ZAA catalyst were $8.39 \%$ and $10.32 \%$, respectively, for liquid products, coke $0.83 \%$ and $0.99 \%$, and residues of $56.89 \%$ and $88.69 \%$. From GC analysis, the selectivity of ZAA and CuO/ZAA catalyst were $61,70 \%$ and $56,39 \%$ for gasoline fraction, $4,82 \%$ and $10,88 \%$ for diesel fraction and $33,48 \%$ and $32.78 \%$ for heavy oil fraction. Impregnated of $\mathrm{CuO}$ on zeolite as catalyst (CUO/ZAA) increased the catalytic activity of catalyst, but the selectivity of $\mathrm{CUO} / \mathrm{ZAA}$ catalysts against gasoline fraction was lower than ZAA catalyst.

Key words: catalyst, catalytic cracking, avocado oil, CuO / ZAA, fuel fraction

DOI: https://doi.org/10.24114/jpkim.v9i2.7619

Minyak bumi merupakan sumber energi dengan sifat tidak terbarukan. Departemen ESDM melaporkan bahwa produksi minyak sebagai bahan bakar saat ini sebesar 55 juta ton/tahun, dimana produksi ini diperkirakan hanya dapat mencukupi kebutuhan BBM di Indonesia selama 10tahun kedepan. Krisis energi yang terjadi di Indonesia dan negara-negara didunia telah mendorong untuk dilakukannya penelitian dan eksplorasi sumber energi baru dan terbarukan sebagai energi alternatif pengganti bahan bakar dari minyak bumi dengan sifat ramah lingkungan (Sihombing dkk., 2014).

Indonesia merupakan negara yang kaya akan sumber daya alamnya, salah satu sumber daya alam yang dapat dimanfaatkan sebagai bahan baku pembuatan bahan bakar cair yaitu minyak nabati dari biji alpukat. Biji alpukat memilki 
kandungan minyak sebesar 15-25\% dengan kandungan tertinggi berupa asam oleat sebesar $70,54 \%$ (Rachimoellah, 2009). Sang (2013) melaporkan bahwa minyak nabati dapat dikonversi menjadi bahan bakar biofuel melalui proses catalytic cracking.

Reaksi catalytic cracking atau perengkahan katalitik adalah reaksi perengkahan menggunakan katalis (katalis heterogen) sebagai material yang mampu mempercepat laju reaksi untuk mencapai kesetimbang dan menghasilkan produk akhir reaksi melalui mekanisme pembentukan ion karbonium (Trisunaryanti, 2014). Catalytic cracking adalah metode umum yang sering digunakan untuk memecah rantai karbon yang cukup panjang menjadi molekul rantai karbon yang lebih pendek dengan menggunakan katalis (Charusiri dan Viditsan, 2005). Metode ini telah digunakan untuk mengkonversi minyak nabati menjadi fraksi karbon ringan dengan proses cracking atau catalytic cracking (Twaiq, 2003; Demirbas, 2003; Wijarnako dkk., 2006; Nasikin dkk., 2009; Mahardiani dkk., 2011 ; Sirajudin dkk., 2012; Santi dkk., 2013; Sihombing dkk., 2014, Wibowo dkk., 2014, Pulungan dkk., 2014, Sihombing dkk., 2016,). Fraksi ringan (light hydrocarbon) yang dimaksud adalah bahan bakar caior setaraf fraksi biogasoline.

Katalis heterogen banyak digunakan dalam industri petroleum, salah satunya adalah zeolit (Trisunaryanti, 2014). Zeolit adalah kristal silikat aluminium dengan struktur jaringan tiga dimensi. Unit struktural utama adalah tetrahedrons $\left[\mathrm{SiO}_{4}\right]^{-4}$ dan $\left[\mathrm{AlO}_{4}\right]^{-5}$, dimana atom silikon dan aluminium diposisikan di tengah, dan atom lebih besar ditempatkan di sudut-sudut tetrahedrons. Kemampuan zeolit untuk mengkatalisis suatu reaksi kimia terutama berhubungan dengan sifatnya sebagai padatan asam karena adanya sisi-sisi asam, baik sisi asam Bronsted maupun Lewis (Trisunaryanti, 2014). Indonesia kaya akan mineral zeolit, namun penggunakan zeolit alam sebagai katalis memerlukan proses aktivasi dan modifikasi untuk meningkatkan aktivitas dan selektitivas nya sebagai katalis. Salah satu sifat yang perlu dimodifikasi adalah sifat keasamannya. Menurut Pulungan dkk. (2011) keasaman zeolit alam dapat ditingkatkan dengan dealuminasi (mengunakan asam mineral sperti $\mathrm{HCl}, \mathrm{HNO} 3$ dan $\mathrm{HF}$ ) maupun dengan mengimpregnasikan logam atau oksida logam tertentu pada pori zeolit.

Berdasarkan hal tersebut diatas, dalam penelitian ini dilakukan preparasi, aktivasi dan modifikasi zeolit alam sebagai katalis dengan mengimpregnasikan oksida logam Cu. Katalis $\mathrm{CuO} / \mathrm{ZAA}$ yang dihasilkan akan digunakan sebagai katalis dalam proses konversi minyak biji alpukat menjadi fraksi bahan bakar melalui proses catalytic cracking dalam reaktor sistem fixe-bed. Penelitian ini diharapkan mampu memberikan variasi material katalis dan produksi bahan bakar biogasoline sebagai bentuk solusi dalam mengurangi masalah energi di Indonesia dimasa depan.

\section{Metode}

Bahan

Bahan-bahan yang digunakan dalam penelitian ini adalah Zeolit Alam (CV. Bratachem), Aquadest, $\mathrm{HCl} 3 \mathrm{M}$ (p.a merck), $\mathrm{H}_{3} \mathrm{PO}_{4}$ (p.a merck), Indikator PP, $\mathrm{NaOH}$ (p.a merck), $\mathrm{AgNO}_{3}$ (p.a merck), $\mathrm{Cu}\left(\mathrm{HNO}_{3}\right) \mathrm{H}_{2} \mathrm{O}$ (p.a merck), gas Nitrogen dan oksigen (PT. Aneka Gas), biji alpukat, Nheksana (teknis), etanol 96\% (p.a. merck).

\section{Alat}

Alat-alat yang digunakan dalam penelitian ini adalah seperangkat alat gelas (pyrex), seperangkat alat refluks, penyaring Buchner, pompa vakum, Hot plate (Cimarec), Piknometer, Termometer (Fischer), furnace, reactor fixed bed, neraca analitik, ayakan 100 mesh, pH indikator, oven, desikator, magnetic bar (Scienceware), regulator, Kromatografi gas (GC- HP-5890 GC Packard Series II, XRD (Shimazdu), dan FTIR (PerkinElmer).

\section{Ekstraksi minyak biji alpukat}

Biji alpukat dicacah, dihaluskan dengan blender lalu dikeringkan dalam oven pada $\mathrm{T}=$ $110^{\circ} \mathrm{C}$ untuk mengurangi kadar air pada biji alpukat. Biji alpukat kering diekstrak dengan pelarut $n$-heksana sehingga menghasilkan minyak dan getah (gum) Kemudian dilakukan pemisahan dengan cara degumming antara ekstrak minyak biji alpukat dengan getah serta pemurnian minyak buji alpukat dengan menambahkan larutan $\mathrm{H}_{3} \mathrm{PO}_{4}$ sebanyak 0,2\% dari berat minyak diaduk dengan pengadukan konstan sampai warna menjadi lebih hitam dan selanjutnya dipisahkan dengan cara sentrifugasi. Kemudian dilakukan netralisasi pada minyak hasil degumming dengan memberi $\mathrm{NaOH}$ $0.1 \mathrm{~N}$ sebanyak $1 \%$ dari berat minyak, lalu diaduk sampai terbentuk dua fasa (sabun dan minyak) kemudian dicuci dengan air hangat $\left(60^{\circ} \mathrm{C}\right)$ sebanyak $10 \%$ dari berat minyak dan diaduk diatas hot plate, lalu dikeringkan dalam oven pada suhu $110^{\circ} \mathrm{C}$ sehingga diperoleh minyak biji alpukat murni. Selanjutnya Minyak biji alpukat yang diperoleh ditentukan sifat-sifatnya yaitu: (Sihombing dkk., 2016) 
Penentuan kadar air minyak biii alpukat

Minyak biji alpukat ditimbang 2-5 gr, lalu dimasukkan ke dalam oven pada temperatur 105 'C selama 3-5 jam kemudian didinginkan dalam desikator dan ditimbang. Perlakuan ini diulangi sampai tercapai berat konstan. Berat sebelum dan sesudah pemanasan dicatat.

Perhitungan:

$$
\text { Kadar air }(\% \mathrm{v} / \mathrm{b})=\frac{W_{1}}{W_{0}} \times 100 \%
$$

Dengan: $W=$ bobot sampel sebelum dikeringkan (gr) dan $w_{1}=$ kehilangan bobot setelah dikeringkan (gr). (Tim Departemen Teknologi Pertanian, 2005).

Penentuan free fatty acid (FFA)

Ak biji alpukat $\pm 5 \mathrm{gr}$ dimasukkan ke dalam erlenmeyer $250 \mathrm{~mL}$, lalu ditambahkan 50 etanol $96 \%$ netral. Campuran minyak etanol dipanaskan sampai sampai suhu $45^{\circ} \mathrm{C}$, kemudian ditambahkan indikator pp 2-3 tetes lalu dititrasi dengan larutan standart $\mathrm{NaOH} 0,1 \mathrm{~N}$ sehingga warna merah muda (titik akhir titrasi.) (Suastuti, 2009).

Perhitungan:

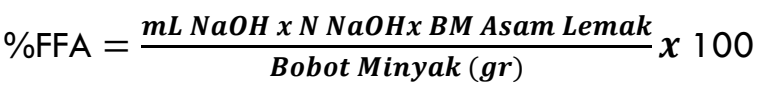

Penentuan berat jenis (density)

Pikonometer dibersihkan dan ditimbang kemudian piknometer diisi dengan aquades bersuhu 20-30 ${ }^{\circ} \mathrm{C}$. Pengisian dilakukan sampai air dalam piknometer meluap dan tidak ada gelembung udara di dalamnya, kemudian piknometer ditutup dan direndam dalam bak air (air es) yang bersuhu $25{ }^{\circ} \mathrm{C}$. Piknometer diangkat dari bak dan dikeringkan dengan kertas pengisap. Piknometer ditimbang dengan isinya dan dihitung densitasnya. Hal yang sama dilakukan untuk sampel minyak biji alpukat (Sihombing dkk., 2016).

Perhitungan:

$\rho=\frac{(\text { massa pikno }+i s i)-(\text { massa pikno kosong })}{\text { Volume pikno }}$

\section{Preparasi zeolit alam}

Zeolit alam dihancurkan dan diayak sehingga didapat zeolit dengan ukuran lolos ayakan 100 mesh. Zeolit alam berukuran 100 mesh ini kemudian dicuci dengan cara merendam dalam aquadest selama 24 jam pada temperatur kamar. Kemudian zeolit disaring dan endapan yang bersih dikeringkan pada temperatur $100^{\circ} \mathrm{C}$ diperoleh sampel zeolit alam (ZA). Sampel zeolit alam (ZA) yang sudah dibersihkan pada penanganan awal dilakukan dealuminasi menggunakan $\mathrm{HCl} 3 \mathrm{M}$ lalu direfluks pada suhu $90^{\circ} \mathrm{C}$ selama 30 menit, larutan hasil refluks disaring, endapan yang dihasilkan dicuci dengan aquades sampai sisa $\mathrm{HCl}$ hilang, ditandai dengan sudah tidak terbentuknya endapan lagi dengan penambahan $\mathrm{AgNO}_{3}$ pada filtrat. Endapan disaring kemudian dikeringkan dalam oven pada suhu $110^{\circ} \mathrm{C}$ selama 3 jam, kemudian dikalsinasi pada suhu $500^{\circ} \mathrm{C}$ dengan dialiri gas Nitrogen sehingga diperoleh zeolit alam teraktivasi asam (ZAA) (Sihombing dkk., 2014).

\section{Pembuatan katalis $\mathrm{CuO} / \mathrm{ZAA}$}

Kristal $\mathrm{Cu}\left(\mathrm{NO}_{3}\right)_{2} \cdot 3 \mathrm{H}_{2} \mathrm{O}$ ditimbang 3,801 $\mathrm{gr}$ lalu dilarutkan dalam aquades, ditambahkan zeolit alam aktif (ZAA) sebanyak $100 \mathrm{gr}$ Lalu keduanya diaduk dalam gelas $250 \mathrm{~mL}$ dan direfluks pada suhu $90^{\circ} \mathrm{C}$ selama 5 jam. Setelah diperoleh sampel $\mathrm{Cu} /$ Zeolit kemudian disaring dan dicuci selanjutnya sampel dikeringkan di dalam oven pada suhu 110 -C selama 3 jam kemudian sampel dioksidasi dengan aliran gas $\mathrm{O}_{2}$ pada suhu $500{ }^{\circ} \mathrm{C}$ selama 3 jam, diperoleh katalis oksida CuO/ZAA (Sihombing dkk., 2016).

Proses catalytic cracking minyak biji alpukat

Proses Catalytic cracking minyak biji alpukat dilakukan dengan rasio katalis : umpan (minyak biji alpukat) 1\% (b/b). Katalis dan umpan ditimbang, selanjutnya katalis diletakkan dalam wadah katalis dan umpan dilektakkan dalam wadah umpan. Kemudian keduanya dimasukkan ke di dalam reaktor fixed-bed yang terbuat dari stainless steel. Setelah itu reaktor dimasukkan ke dalam furnace dan dipanaskan pada suhu $450^{\circ} \mathrm{C}$ dan uap umpan yang terbentuk dialirkan ke dalam reactor dan reaksi dilakukan selama 1 jam. Produk yang terbentuk dialirkan melalui selang silikon dengan melewati kondensor dan produk cair yang diperoleh lalu dianalisis dengan GC (Sihombing dkk., 2016).

\section{Hasil dan Pembahasan}

Ekstraksi minyak biii alpukat

Pada penelitian ini, minyak biji alpukat dihasilkan dengan metode sokhlet ekstraksi padatcair (leaching) menggunakan pelarut n-heksana sebagai pelarut yang baik untuk mengesktraksi minyak dari biji alpukat. pelarut. Minyak biji alpukat dari hasil ekstraksi diperoleh randemen sebesar $9.57 \mathrm{gr}$ dari sampel biji alpukat sebanyak 100 gr. Menurut Rachimoellah (2009) Banyaknya kandungan minyak biji alpukat tergantung pada keadaan geografis dari sifat ekologis dan ras dari 
biji alpukat tersebut yang dibagi kedalam tiga tipe alpukat diantaranya adalah ras Guatemala mempunyai kandungan minyak sebesar 10-13\%, dan ras Mexico sebesar 15-25\% sedangkan buah Carrebian mempunyai kandungan lemak sebesar $2,5-5 \%$. Selanjutnya minyak biji alpukat yang diperoleh ditentukan sifat-sifatnya.

Penentuan karakteristik minyak biii alpukat

Berikut disajikan perbandingan parameter hasil penelitian dari ketiga penentuan karakteristik minyak biji alpukat yang diperoleh pada Tabel 1 .

Tabel 1

Perbandingan parameter hasil penelitian dari ketiga penentuan karakteristik minyak biji alpukat

\begin{tabular}{cccc}
\hline $\begin{array}{c}\text { Parameter Minyak } \\
\text { Biji Alpukat }\end{array}$ & $\begin{array}{c}\text { Hasil } \\
\text { Penelitian }\end{array}$ & $\begin{array}{c}\text { Standart } \\
\text { Mutu }\end{array}$ & $\begin{array}{c}\text { Parameter } \\
\text { Pembanding }\end{array}$ \\
\hline Kadar Air (\%V) & $0,04 \%$ & Maks & SNI04-7182- \\
& & $0,05 \%$ & 2006 \\
FFA (\%) & $0,64 \%$ & $0,36-$ & Rachimoellah \\
& & $0,82 \%$ & \\
Berat Jenis (25) $\mathbf{C})$ & 0,8854 & $0,915^{-}$ & Rachimoellah \\
& $\mathrm{g} / \mathrm{mL}$ & $0,916 \mathrm{~g} / \mathrm{mL}$ & \\
\hline
\end{tabular}

Hasil asil analisis GC menunjukkan bahwa kromatogram FAME minyak biji alpukat diketahui mengandung asam- asam lemak yaitu ( $\mathrm{Cl6:0)}$ asam palmitat dengan konsentrasi sebesar 12.50 $\%$, (C15:1) asam CIS dengan konsentrasi sebesar $6.19 \%$, (C18:1) asam oleat dengan konsentrasi sebesar $69.49 \%$ serta (C18:2) asam linoleat dengan konsentrasi sebesar $11.82 \%$, dan (C20:0). Hasil ini sesuai dengan penelitian yang dilakukan Rachimoellah dkk. (2006).

\section{Karakterisasi katalis}

Untuk melihat pengaruh perlakuan aktivasi kalsinasi dan modifikasi dengan pengembanan logam Cu ke dalam pengemban zeolit alam maka dalam penelitian dilakukan karakterisasi meliputi analisis IR dan XRD. Analisis IR dilakukan untuk mengetahui pengaruh aktivasi dan kalsinasi terhadap struktur kerangka zeolit. Aktivasi dengan $\mathrm{HCl} \quad 3 \mathrm{M}$ dapat menyebabkan terjadinya dealuminasi zeolit yaitu lepasnya Al dari kerangka zeolit sehingga rasio Si:Al meningkat. Peningkatan rasio Si:Al meningkatkan keasaman zeolit. Terjadinya dealuminasi dalam kerangka zeolit diamati melalui pergeseran bilangan gelombang gugus $\mathrm{TO}_{4}$ pada kisaran $1000-1100 \mathrm{~cm}^{-1}$. Spektra IR dari ZA, ZAA dan CuO/ZAA dapat dilihat pada Gbr 1 .

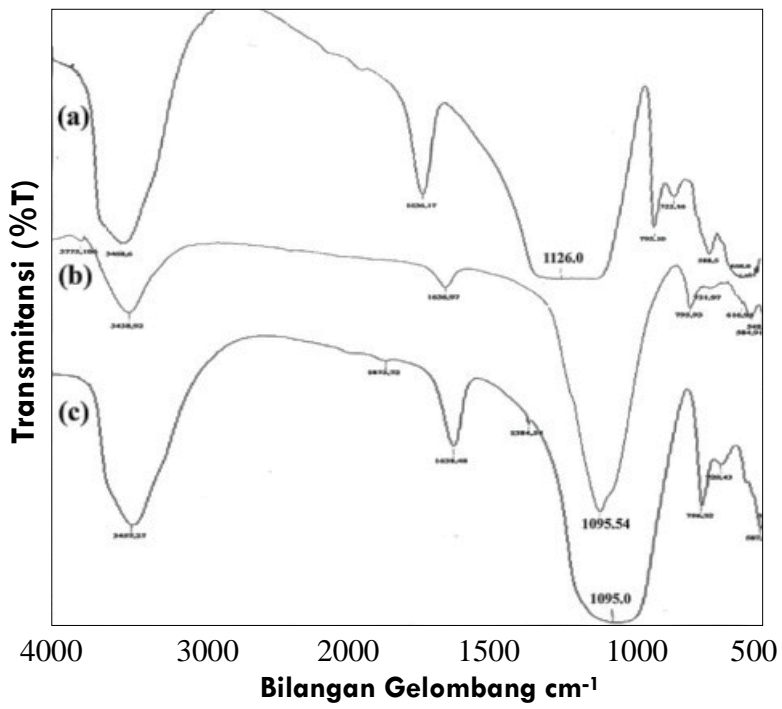

Gbr 1. Spektra IR(a) ZA, (b) ZAA, (c) CuO/ZAA

Dari Gbr 1 dapat dilihat bahwa zeolit sebelum perlakuan pengasaman (ZA) memiliki bilangan gelombang vibrasi rentangan asimetris pada $1126,0 \mathrm{~cm}^{-1}$ setelah diaktivasi (ZAA) memiliki bilangan gelombang bergeser pada $1095,54 \mathrm{~cm}^{-1}$, hal ini sebagai akibat terjadinya dealuminasi atau terjadi pemutusan ikatan Al-O yang menyebabkan ion Al keluar dari kerangka zeolite, peristiwa ini juga menghasilkan bentuk tekukan tajam dan lebih sempit, namun setelah penambahan oksida logam katalis CuO/ZAA terjadinya pelebaran spektra namun masih pada bilangan gelombang 1095,0 $\mathrm{cm}^{-1}$. Efek dealuminasi yang terjadi pada zeolit meyebabkan meningkatnya rasio $\mathrm{Si} / \mathrm{Al}$ dan menyebabkan zeolit lebih bersifat hidrofobik dan memiliki sifat thermal yang lebih besar. (Sriningsih dkk. 2014).

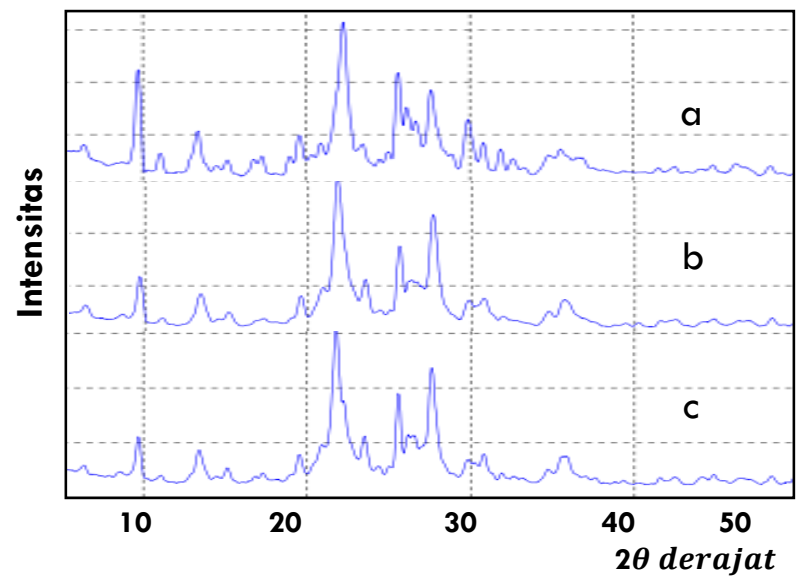

Gbr 2. Difraktogram katalis (a) ZA, (b) ZAA dan (c) $\mathrm{CuO} / \mathrm{ZAA}$ 
Analisi sinar $X \quad$ (XRD) digunakan untuk menentukan jenis kristal dan kristanilitas dari suatu material. Hasil analisis XRD pada Gbr 2 menunjukkan zeolit alam yang digunakan termasuk kedalam jenis zeolit mordenit. Hal ini sesuai dengan hasil penelitian yang dilakukan oleh Trisunaryanti dkk (1996) melaporkan bahwa komposisi utama zeolit alam Indonesia adalah mordenit sekitar 70\%. Puncak-puncak utama difraktogram berada pada 20-30 $2 \theta$ (derajat).

Hasil analisi XRD pada Gbr 2 dapat dilihat perbandingan harga intensitas pada sudut $2 \theta$ (derajat) yang sama. Hal ini menunjukkan bahwa katalis ZAA memiliki intensitas puncak difraktogram yang lebih tinggi dibanding ZA. Hal ini dikarenakan pada ZAA dilakukan proses pencucian dan pengasaman sehingga padatan katalis menjadi lebih bersih dari pengotor-pengotor sehingga meningkatkan kristalinitasnya.

Pengaruh dari pengembanan oksida logam $\mathrm{CuO} /$ ZAA menunjukkan peningkatan pada puncakpuncak utama difraktogram. Perubahan ini terdapat pada $2 \theta$ (derajat) ZAA 21,8638 dengan intensitas 539 berubah menjadi 21,7863 dengan intensitas 559 pada $\mathrm{CuO} / \mathrm{ZAA}$, lalu pada $2 \theta$ (derajat) ZAA 25,5920 dengan intensitas 270 berubah menjadi $2 \theta$ (derajat) pada CuO/ZAA 25,5711 dengan intensitas 301 dan yang terakhir yaitu pada $2 \theta$ (derajat) ZAA 27,6564 dengan intensitas 390 berubah menjadi $2 \theta$ (derajat) pada $\mathrm{CuO} /$ ZAA 27,6268 dengan intensitas sebesar 397. Dari uraian di atas dapat dinyatakan bahwa perlakuan aktivasi asam, kalsinasi pada zeolit alam tidak merusak struktur kristal zeolit dan pengembanan oksida logam yang terdistribusi merata pada padatan pengemban zeolit serta diduga telah terjadi penataan ulang struktur zeolit dan terbentuknya pori-pori baru.

\section{Katalitik cracking minyak biji alpukat}

Produk yang dihasilkan dari proses cracking minyak biji alpukat dapat terdiri dari produk cair, kokas, gas dan residu. Terjadinya proses cracking minyak biji alpukat selain ditunjukkan dari kromatogram GC dapat juga diamati dari perubahan warna sampel dari kuning pekat menjadi kuning kehijauan dan densitas dari produk cair yang dihasilkan lebih rendah dari sampel minyak. Nasikin dkk (2009) menjelaskan bahwa penurunan densitas dari minyak sebelum dan sesudah proses cracking adalah akibat sebagain dari molekul trigliserida mengalami pemutusan menjadi molekul yang yang lebih kecil. Persentase dari tiap produk yang dihasilkan dasajikan pada Tabel 2.
Dari Tabel 2 dapat dilihat bahwa katalis yang terembankan oksida logam CuO/ZAA menghasilkan produk cair lebih besar dibandingkan dengan katalis ZAA. Katalis $\mathrm{CuO} / Z A A$ menghasilkan produk cair sebesar $10,32 \%$ sedangkan pada katalis ZAA dihasilkan sebesar 8,39\%. Dengan pengembanan oksida logam pada zeolit membuka kerangka pori yang aktif dan meningkatkan keasaman katalis sehingga meningkatkan aktivitas katalitiknya dan kemampuannya untuk menghasilkan produk cair dalam jumlah yang lebih besar. Sihombing dkk. (2014) melaporkan bahwa impregnasi logam Ni, Co dan Mo pada katalis zeolit alam meningkatkan konversi produk cair dari hasil cracking MEFA minyak dedak padi. Hal yang sama juga dikemukan oleh Wibowao dkk. (2014) dimana katalis $\mathrm{Ni}$ /Zeolit $\mathrm{Y}$ memiliki aktivitas dan selektivitas yang lebih baik dibandingkan dengan katalis ZY dalam proses cracking minyak biji karet.

Untuk melihat selektivitas katalis terhadap fraksi bensin dan disesel maka dilakukan analisis GC terhadap produk cair yang dihasilkan. Distribusi fraksi bensin diesel dan minyak berat pada masing-masing katalis disajikan pada Gbr 3.

\section{Tabel 2}

Hasil cracking minyak biji alpukat berupa produk cair, gas, dan kokas

\begin{tabular}{cccccc}
\hline Katalis & $\begin{array}{c}\text { Suhu } \\
\left({ }^{\circ} \mathrm{C}\right)\end{array}$ & $\begin{array}{c}\text { Produk } \\
\text { Cair } \\
(\% \mathbf{\%} / \mathbf{b})\end{array}$ & $\begin{array}{c}\text { Kokas } \\
(\% \mathbf{b})\end{array}$ & $\begin{array}{c}\text { Residu } \\
(\% \mathbf{b} / \mathbf{b})\end{array}$ & $\begin{array}{c}\text { Gas } \\
(\% \mathbf{b} / \mathbf{b})\end{array}$ \\
\hline ZAA & 450 & 8,39 & 0,83 & 56,89 & 33,89 \\
CuO/ZAA & 450 & 10,32 & 0,99 & 88,69 & - \\
\hline
\end{tabular}

Untuk memisahkan fraksi bensin dan diesel, kedalam sampel dilakukan splitting dedngan dodekana. Dari hasil GC diperoleh tiga komponen dalam produk cair yaitu fraksi bensin dengan waktu retensi $(t)<10$ menit, fraksi disesel $t>10$ menit, dan fraksi mkinyak berat $t>20$ menit. Selektivitas katalis terhadap hasil konversi pada proses katalitik cracking ditampilkan pada Gbr 3.

Pada Gbr 3 diperoleh informasi bahwa katalis ZAA memiliki selektivitas tertinggi terhadap fraksi bensin mencapai $61,70 \%$ dan katalis CuO/ZAA hanya sebesar 56,34\%. Sementara untuk fraksi diesel masing masing katali ZAA dan CuO/ZAA sebesar 4,82\% dan 10,88\%. Dari data ini dapat dinyatakan bahwa pengembanan oksida logam $\mathrm{CuO}$ pada pengemban zeolit meningkatkan aktivitas katalitik katalis (hal ini dapat dilihat pada 
Tabel 2, hasil konversi produk cair katalis $\mathrm{CuO} / \mathrm{ZAA}$ lebih besar dari ZAA) namun selektivitas katalis terhadap fraksi bensin masih rendah dibandingkan ZAA.

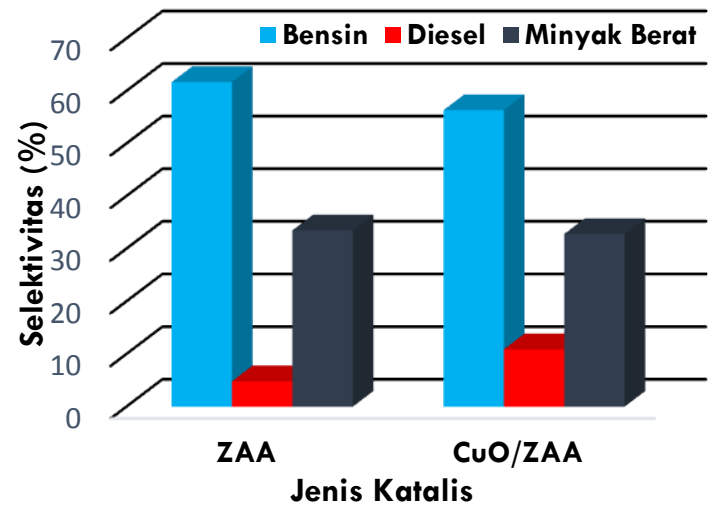

Gbr 3. Grafik distribusi fraksi bensin, diesel dan minyak berat pada katalis ZAA dan CuO/ZAA

\section{Kesimpulan}

Dari penelitian yang telah dilakukan diperoleh kesimpulan sebagai berikut: (1) pengembanan oksida logam $\mathrm{CuO}$ pada bahan pengemban zeolit sebagai katalis (CuO/ZAA) meningkatkan aktivitas katalitik katalis; dan (2) selektivitas katalis CuO/ZAA terhadap fraksi bensin masih lebih rendah dibandingkan dengan katalis ZAA.

\section{Daftar Pustaka}

Charusiri, S. \& Vitidsant, T. (2005). Kinetic study of used vegetable oil to liquid fuels over sulfated zirconia. Energie and Fuels, 19: 1783-1789.

Demirbas, A. (2003). Fuel conversional aspect of palm oil and sunflower. Energy Sources Journal, 25(5) Taylor \& Francis Publisher.

Knothe, G. (2013). Avocado and olive oil methyl esters. Biomass and Bioenergy, 58:143-148.

Mahardiani, L., Kurniawan, E., Trisunaryanti, W. \& Triyono. (2011). Hidrorengkah metil ester asam lemak (MEPO) menggunakan zeolit alam teraktivasi. J. Molekul, 6(2): 105-112.

Nasikin, M., Susanto, H.B., Hirsaman, M.A. \& Wijarnoko, A. (2009). Biogasoline from Palm oil by Stimultaneous cracking and hydrogenation reactio over $\mathrm{NiMo} /$ zeolite catalyst. World Applied Sciense Journal, 5:7479.

Pulungan, A.N. (2014). Konversi cashew nut shell liquid (Cnsl) dari kulit biji mete menjadi fraksi bahan bakar cair melalui proses catalytic hydrocracking. Jurnal Pengabdian Kepada Masyarakat, 20: 77-80.

Rachimoellah, H.M., Resti, D.A. \& Ali, Z. (2009). Production of biodiesel through transesterification of avocado (Persea gratissima) seed oil using base catalyst. Jurnal Teknik mesin, 11:85-86.

Santi, D. (2013). Modifikasi zeolit alam sebagai katalis dan uji aktivitas katalis dalam reaksi hidrorengkah minyak kulit jambu mete (Anacardium occidentale) menjadi biogasoline dan biodiesel. Journal ISTECH, 5(2):104-108.

Setiadi \& Pertiwi, A. (2007). Preparasi dan karakterisasi zeolit alam untuk konversi senyawa abe menjadi hidrokarbon. Prosiding Konggres Dan Simposium Nasional Kedua Mkics 2007 Departemen Teknik Kimia, Fakultas Teknik Universitas Indonesia, Depok, ISSN: 02164183.

Sihombing, J.L., Pulungan, A.N., Wibowo, A.A. \& Nasution, H.I. (2016). Catalytic hydrocracking minyak biji alpukat menjadi bahan bakar cair menggunakan katalis Zno/Zaa. Prosiding Seminar Nasional Kimia dan Pendidikan Kimia, ISBN: 9786024320042: 89-95.

Sihombing, J.L., \& Pulungan, A.N. (2014). Konversi minyak dedak padi menjadi biogasoline melalui proses catalytic cracking (via esterifikasi dan transesterifikasi). Jurnal Penelitian Saintika, 15:132-142.

Sirajudin, N., Jusoff, K., Yani, S., Ifa, L. \& Roesyadi, A. (2012). Biofuel production from catalytic cracking palm oil. World Applied Sciense Journal, 26: 676-71.

Sriningsih, W., Saerodii, M. G., Trisunaryanti, W., Armunanto, R., \& Falah, I.I. (2014). Fuel production from LDPE plastic waste over natural zeolite supported $\mathrm{Ni}, \mathrm{Ni}-\mathrm{Mo}, \mathrm{Co}$ and Co-Mo metals. Procedia Environmental Sciences, 20:215-224.

Suastuti, N.D.A. (2009). Kadar air dan bilangan asam dari minyak kelapa yang dibuat dengan cara tradisional dan fermentasi. Jurnal Kimia, 3(2):69-74.

Tim Departemen Teknologi Pertanian. (2005). Prosees pembuatan minyak jarak sebagai bahan bakar alternative. Fakultas Pertanian Universitas Sumatera Utara, Medan: 24-25.

Trisunaryanti, W. (2014). Material katalis dan karakterisasinya. UGM Press, Yogyakarta.

Trisunaryanti, W., Shiba, R., Miura, M., Namura, M., Nashiyama, N. \& Matsukata, M. (1996). Characterization and modification of indonesian natural zeolit and their properties for hidrocracking of a parafin. J. Jpn. Ints. Petr, 39: 2025-2032. 
Twaig F.A., Mohammed, A. \& Bhatia, S. (2003). Liquid hydrocarbon fuels from palm oil by catalytic cracking over aluminasilicate mesoporous catalytic with various $\mathrm{Si} / \mathrm{Al}$ ratio. J. Micro and Meso Mat, 64:95-107.

Wibowo, A.A., Firdausyah, S., Haijah, S., Dwiyanti, D., Layla, J., Sihombing, J.L. \& Pulungan, A.N. (2014). Study of rubber seed oils hydrocracking into biogasoline and diesel fraction over the combination Y-zeolite and $\mathrm{Ni}$.
Proceeding The First International Seminar on Trends in Science and Science Education, ISBN 978-602-91 15-37-6: 132-140

Wijanarko, A., Dadi, A.M., \& Nasikin, M. (2006). Produksi biogasoline dari minyak sawit melalui reaksi perengkahan katalitik dengan katalis $Y$ alumina. Makara Teknologi, 10:51-60. 